\title{
The Application of Cooperative Learning Theory in College English Teaching
}

\author{
Lina Ma \\ Zhengzhou University of Industrial Technology, Xinzheng, Henan, 451100
}

\begin{abstract}
Keywords: College English, Classroom Teaching, Cooperative Learning Theory
\end{abstract}
\begin{abstract}
The ultimate goal of language learning is to communicate, cooperative learning theory, also known as group learning, collaborative learning, etc., in the classroom teaching students will be divided into a number of learning groups, members of the group to learn mutual aid. Cooperative learning theory is an advanced teaching theory and practice mode, which can cultivate students' cooperative learning consciousness, improve their cooperative learning skills and improve the teaching environment. The use of cooperative learning in college English teaching can highlight the practical experience of English communication, emphasizing students 'exchange and mutual help, and help to deepen students' memory and understanding, so as to improve their learning effect. The article mainly discusses the concrete application of cooperative learning theory in college English teaching.
\end{abstract}

\section{The Connotation of Cooperative Learning}

The so-called cooperative learning refers to the students in the learning group to carry out mutual aid cooperative learning activities, through the learning team to guide students through common learning practice in the heterogeneous cooperation group to promote their own learning behavior, so that students through cooperative interpersonal relationships to reach a common learning objectives to promote their cognitive, emotional common development, so as to improve the learning effect. Cooperative learning theory must have five elements, namely, positive interdependence, face interaction, accountability, social skills and group reflection. Therefore, the application of cooperative learning theory highlights the practical experience of students in the learning process, which coincides with the characteristics of English learning emphasizes practicality. English learning students through a large number of training to master a specific application of knowledge points, students need to repeatedly memory, timely correction, continuous practice, in order to achieve the purpose of consolidating language information. In the traditional teaching mode, the language environment of English is mostly the interaction between teachers and students in the classroom, which is not conducive to the application of language communication. The cooperative learning needs students to ask questions, debates and explanations, so as to create more language input for students, output the opportunity to consolidate the learning effect. In addition, cooperative learning theory also emphasizes student communication and interaction. Cooperative learning mainly in the collective way to complete the task of learning, not only reduces the individual students 'learning pressure, get more support and encouragement of peers, and can alleviate the students' fear of teachers and enhance their learning self-confidence. In the process of cooperative learning, students can show their ability, opinions and interests and cooperate with each other to broaden the learning knowledge, develop innovative thinking ability, and ensure the exchange effect in the form of compulsory. It can be seen that the theory of cooperative learning is truly a "learning-centered" teaching principle, creating a solidarity, mutual help, relaxed and interactive learning environment for students to communicate in English in a good learning atmosphere. And cooperation, the formation of knowledge construction, the development of thinking ability, master communication skills, thereby enhancing their overall quality. 


\section{The Theoretical Basis for Cooperative Learning}

In college English teaching, the theoretical basis of cooperative learning includes subjective theory, communication and respect needs theory, constructivism theory and so on. In the subjective education theory, the student is a development subject rather than an educational object in the traditional teaching mode, and the group cooperative study emphasizes the mutual interaction between the students, the independent study, the self- Truly highlight the students in the study of the dominant position, so as to stimulate their learning initiative and enthusiasm. The interaction and respect need the theory that "communication", "cooperation" is the essence of teaching, and teachers and students interaction, common development is the ultimate goal of teaching, and cooperative learning to create a democratic, equal learning atmosphere to the greatest extent reflects the students and students, teachers and students in the interaction of mutual respect, so as to stimulate students' interest in learning. In addition, the constructivist theory holds that students are the main body of information processing, which is not the passive recipient of external stimuli, but the subject of active construction. Students are based on their own knowledge and experience, through the environment, the realization of the meaning of the construction. Cooperative learning theory creates an equal classroom dialogue between teachers and students, the atmosphere of students' conversations, respect for individual differences in students, and the application of formative evaluation to enable students to construct knowledge in the recent development area.

\section{The Specific Application of Cooperative Learning Theory in College English Teaching}

Specifically, the application of cooperative learning theory in college English teaching includes the following links:

Student Grouping. Cooperative learning theory in science, reasonable learning grouping is to ensure the effectiveness of the basis of the students, the group should be reasonable to control the size of the group to ensure that each group members can effectively participate in learning activities. Related literature research reports that the team to learn the best staff in the 3-6 people, to ensure that each member of the opportunity to participate in learning tasks are equal. The group should also follow the principle of heterogeneous grouping, fully analyze the students' gender, grades, knowledge system, personality, behavior habits and learning ability and other factors, the same learning group to include different levels, different levels of students to ensure that the group Complementary advantages and fairness between groups. In the process of cooperative learning, different levels of the team members can be between the good mutual help, to help students' better completion of learning tasks. After the grouping, the specific roles and tasks should be set according to the learning ability of the members of the group. The organizers are mainly responsible for the arrangement of learning activities in the group and maintain the discipline of the group. The encourageers will encourage each member to participate in the discussion activities. Observers mainly record the focus of the group and the completion of the members of the task, after the end of the activities to feedback to the members of the relevant information; report to the class, the teacher reported the results of the group learning.

Group Cooperative Learning Design. In the actual group of cooperative learning, the commonly used forms of learning include the group writing story games, English film dubbing, English racing games and so on. Students have a wealth of imagination, and the preparation of the story can further develop students' imagination, and interesting. So the teacher can combine the content of the textbook, according to the text of the characters set, the story, so that students play their imagination to write their own interest in the story. The psychological characteristics of college students determine that they have a strong curiosity about anything, so the story can fully mobilize the enthusiasm of the students, and in the process of writing the story of the students' English writing ability is bound to be greatly improved, not only to students to learn the fun of English, but also to achieve the initiative of students to develop. In addition to writing the story, the English film is also a student is very interested in one of the activities, and dubbing through imitation, recitation 
exercises can effectively improve the students' oral skills. A complex, many people, each character is between the intricate relationship, the teacher can choose a suitable film clips, members of the group by the autonomous distribution of roles, each person carefully listen to the lines of characters, and then imitate their voice, Intonation, recite lines, the whole process of students can better grasp the spoken English in the continuous, provincial reading and skip skills, the oral level and listening level will be improved. In addition, the group's cooperative learning activities include group breakout competition, English song singing competition, English poetry recitation contest, English debate and so on. These activities can be language learning into the entertainment, so as to create a good learning atmosphere, to stimulate students to learn interest to help students quickly master and consolidate the language knowledge.

The Classroom Effect Evaluation. Classroom learning effect evaluation should try to be objective, comprehensive, attention to the evaluation of student learning process, so that quantitative evaluation and qualitative evaluation of the organic combination to ensure the continuity of cooperative learning. The evaluation methods include student self-evaluation, group mutual evaluation, group evaluation, teacher comment and other forms, highlighting the students in the process of cooperative learning emotional attitude, participation, and ultimately according to their academic performance to enhance their English language ability the degree of evaluation, so that students reflect on their own learning situation, and compare each other, avoid weaknesses, timely adjustment of learning strategies to get greater progress. Of course, the group to learn to pay full attention to the collective performance of each group to detect the team members of the learning effect, making the evaluation method more specific, more detailed evaluation of the content. The evaluation methods include quantitative evaluation and qualitative evaluation. The whole process of cooperative learning involves quantitative evaluation, such as whether the pre-class preparation is completed on time, how to complete the quality, the main performance of the classroom evaluation of the results of collaborative learning results, extracurricular self-study whether the development of the English study plan, plan to complete the situation and so on, different learning links according to their importance to the proportion of their ratings are different, such as pre-class preparation accounted for $10 \%$ of the total score, classroom performance accounted for 35\% , Extracurricular self-study accounted for $25 \%$ of the total score, unit knowledge points accounted for $40 \%$ of the total score. In addition to quantifiable indicators, students' emotional attitudes, participation, progress in English and other content cannot be quantified, can be used to complement the qualitative evaluation method, the teacher more use of incentive language to improve student learning initiative and effectiveness.

\section{The Considerations of Cooperative Learning}

Of course, any kind of teaching methods are not omnipotent, in the cooperative learning rate should also pay attention to avoid the following learning errors: on the one hand to avoid the cooperative learning into "collective learning." College English includes more refinement courses, such as oral English language training and English expression, English writing is to develop students' English writing ability, English reading is divided into extensive reading and intensive reading and so on, so cooperative study should pay attention to the development of targeted learning objectives, focusing on the ability of students to develop a certain aspect. In the same learning group in different students of their English foundation is not the same, the teacher should pay attention to guide students not to understand the cooperative learning as "collective learning" to avoid the students into the "test and teaching" of the errors, only the test knowledge point as the focus of learning content, but not really master the correct English learning methods. On the other hand, avoid cooperative learning flowing in form. At this stage, the popularity of cooperative learning has been more extensive, but many teachers in the application of cooperative learning only when the introduction of the classroom, but did not really understand the essence of cooperative learning. Cooperative learning is not a simple group study, reduce the large class teaching, but to provide students with more opportunities for mutual exchange, so that students in the process of communication skills, experience the emotions, so as to improve their overall quality. 
In short, in the new curriculum reform continues to advance today, cooperative learning theory in the classroom teaching more and more widely, in stimulating students to learn interest, improve the effectiveness of classroom teaching advantages are more and more prominent, but any kind of teaching Theory has its own shortcomings and limitations, cooperative learning is not universally applicable, therefore, we learn from cooperative learning strategies to avoid entering the form of misunderstanding, the teacher in the classroom teaching process should be with the students the actual combination of specific, consider whether the content of cooperation is necessary, strengthen the guidance, encourage innovation, establish a good cooperative learning order, in order to play the role of cooperative learning, improve teaching effectiveness.

\section{References}

[1] Zeng Jianlan. Discussion on the principles of pragmatic cooperation and politeness and its application in English teaching[J]. Journal of Insurance Vocational College, 2016 (2)

[2] Guo Chen. The application of conversational cooperation principle in English teaching[J]. Chinese Journal of Education, 2015 (8)

[3] Zhang Yu. Cooperative principles in the use of guidelines in English teaching[J]. Foreign Language Teaching Research, 2016 (7)

[4] Shao Qinyu, He Li. Study on the Construction and Empirical Study of College English Cooperative Learning Model Based on the Network and Classroom Mixed Environment [J]. Foreign Language Teaching, 2014, (3)

[5] Pan Linlin, Song Yi. Cooperative learning and speculative ability training[J]. Foreign language and foreign language teaching, 2016, (2)

[6] Wu Ronghui, He Gaoda. Application of Cooperative Learning in College English Writing Teaching [J]. Foreign Language Teaching, 2014, (5)

[7] Wang Lifang. Research on the Application of Group Cooperative Learning in College Students' Classroom - Taking the Social Work Specialty of China Institute of Labor Relations as an Example [J]. Journal of Hubei Normal University (Philosophy and Social Sciences), 2014, (3) 